\title{
ARTIGO
}

\section{O QUE OS JOVENS PODEM ESPERAR DA REFORMA DO ENSINO MÉDIO BRASILEIRO?}

Geraldo Leão* Universidade Federal de Minas Gerais (UFMG), Belo Horizonte - MG, Brasil

RESUMO: $\mathrm{O}$ artigo aborda traços recorrentes do ensino médio brasileiro com o objetivo de refletir sobre a proposta de sua reestruturação contida na Lei 13.415/17. Sem a preocupação de tecer uma análise exaustiva dessa lei, o texto tem como foco discutir aspectos que caracterizam o ensino médio brasileiro e que estão presentes na atual legislação. Em seguida discute as suas implicações para a relação dos jovens com esse nível de ensino no contexto atual de sua massificação. $O$ ensino médio é caracterizado como um campo de disputas em torno de diferentes projetos educacionais que se diferenciam em termos de concepções políticas e das perspectivas em relação às questões das juventudes brasileiras. A reforma em andamento no Brasil revela outros interesses para além de atender às demandas dos jovens. Palavras-chave: Ensino Médio. Políticas educacionais. Juventude.

\section{WHAT CAN YOUNG PEOPLE EXPECT FROM BRAZILIAN'S HIGH SCHOOL REFORM?}

ABSTRACT: This article addresses Brazilian Secondary Education's recurrent features, aiming to reflect on its restructuring proposal contained in Law 13.415/17. With no concern of making an exhaustive analysis of this law, the text focuses on discussing aspects that characterize Brazilian High Schooland that are present in the current legislation. The article then discusses its implications to young people's relationship with this level of education in the current context of its massification. Secondary Education is characterized as a field of disputes around different educational projects that differ in terms of political conceptions and perspectives regarding issues lived by Brazilian youth. The analysis concludes that the ongoing reform in Brazil has other interests beyond youth's demands.

Keywords: High school. Educational policies. Youth.

" Doutor em Educação pela Universidade de São Paulo (USP). Professor Associado da Faculdade de Educação da Universidade Federal de Minas Gerais (UFMG). Pesquisador do Observatório da Juventude da UFMG. E-mail: < glea02001@gmail.com>. 
O debate aberto com as últimas medidas anunciadas pelo Governo Federal, em relação ao ensino médio, revela muitas divergências sobre os rumos que deverá tomar esse nível de ensino no país. ${ }^{1}$ Os atores envolvidos manifestam diferentes pontos de vistas que partem de interesses e expectativas conflitantes em relação ao tema, dependendo do lugar de onde se fala. Apesar disso, parece haver um consenso construído socialmente em torno da ideia de que "reformar o ensino médio é urgente". (MOLL e GARCIA, 2014).

Considero importante iniciar uma análise sobre o tema explorando um pouco essa imagem da urgência, já que ela também foi usada como argumento central para a edição da MP 746/2016 recentemente aprovada como Lei 13.415/17. Porque é urgente reestruturar o ensino médio? Pensar o ensino médio brasileiro e a "urgência" de sua reforma exige recuperar um traço marcante na história da escola pública no Brasil. Segundo Jaqueline Moll e Sandra Garcia (2014, p. 7):

A história da escola pública brasileira seguiu essa trilha. TARDIA, DESIGUAL E INSUFICIENTE, ${ }^{2}$ tanto em termos do tempo educativo, quanto nas dimensões formativas contempladas, distribui-se de modo assimétrico, privilegiando alguns em detrimento da maioria.

Tal história é a expressão no campo educacional de uma formação social calcada no privilégio do nome e na meritocracia do berço. Somos filhos de uma tradição onde a frase "Você sabe com quem está falando?" ou a imagem do "jeitinho brasileiro" são expressões da naturalização das desigualdades sociais e econômicas. Não é isso que dizem os jovens quando relatam suas dificuldades em relação á inserção no mercado de trabalho? "Falta QI: quem indique!" Ou quando buscam estratégias de acesso a uma boa escola pública, às vezes forjando comprovações de endereços falsos, porque é preciso morar em um "lugar nobre" para ter direito a uma escola minimamente adequada?

É nessa perspectiva que as autoras falam de um "cenário de urgências": problemas sociais, que se traduzem em dramas pessoais e demandas públicas - conseguir um emprego, concluir a educação básica, ter acesso à habitação, ter acesso ao ensino superior ou a uma formação técnica - que não se resolvem e se acumulam governo após governo.

Essa chegada "tardia, desigual e insuficiente" do Estado como provedor da educação no Brasil, que já refletem em sua origem uma formação social desigual e autoritária, gerou uma série de contradições e dilemas que percorrem a história do ensino médio brasileiro, 
que chamamos hoje de "crise do ensino médio": financiamento insuficiente, a desvalorização dos professores, sucateamento das escolas, falta de identidade, baixo rendimento escolar etc. Poderão as reformas propostas superar esse quadro?

Sobre o pretexto de instituir a "Política de Fomento à Implementação de Escolas de Ensino Médio em Tempo Integral", a Lei 13.415/17 altera vários artigos da LDB 9394/96, a Lei 11.494/07 (que regulamenta o Fundo de Manutenção e Desenvolvimento da Educação Básica e de Valorização dos Profissionais da Educação), além da CLT e outros decretos. Não se pretende produzir uma análise exaustiva da legislação, uma vez que vários estudos e análises têm sido publicados sobre o tema. ${ }^{3}$ Para melhor compreensão de alguns argumentos que serão abordados posteriormente, ressalto apenas os aspectos considerados centrais na proposta de reforma em curso e que estão contidos na lei. Ela amplia progressivamente a carga horária diária no ensino médio para 1.400 horas/ano $(7$ horas/dia), devendo passar a no mínimo 1.000 horas/ano (5 horas/dia) no prazo de cinco anos. Para o caso dos estudantes que frequentam as escolas à noite, a lei prevê apenas a "oferta" da Educação de Jovens e Adultos e do ensino regular de acordo com as condições dos educandos, sem maiores detalhes.

Além da ampliação do tempo, a lei institui cinco "itinerários formativos": 1) Linguagens e suas tecnologias, 2) Matemática e suas tecnologias, 3) Ciências da natureza e suas tecnologias, 4) Ciências humanas e sociais aplicadas e 5) Formação técnica e profissional. Tais percursos serão ofertados por meio de diferentes arranjos curriculares a critério dos sistemas de ensino, segundo suas possibilidades e relevância para o contexto local.

Outro eixo central da lei se refere ao Ensino Técnico e Profissional de Nível Médio. Quanto a esse aspecto, a legislação abre a possibilidade de parcerias com o setor privado, a oferta da educação à distância, o reconhecimento de experiências de trabalho no setor produtivo e a possibilidade de contratação de docentes que comprovem notório saber. Esses pontos da lei, entre outros, configuram, então, um processo de flexibilização que atende aos interesses dos sistemas de ensino e do mercado de trabalho. A redução de custos para o Estado e a privatização, por meio da transferência de recursos da educação pública para o setor privado, são os pilares da proposta.

Esse artigo discute algumas propostas para o ensino médio brasileiro, trazidas à cena pela atual proposta de reestruturação. Elas traduzem disputas em torno de soluções para o que se considera problemas do ensino médio. Em sua primeira parte o artigo traz alguns 
traços recorrentes na história do ensino médio brasileiro, especialmente o embate: universalização versus seletividade nesse nível de ensino. Em seguida, discute aspectos da relação entre jovens com o ensino médio, buscando, a partir do resgate de resultados de alguns estudos sobre as suas demandas, visões e expectativas acerca desse nível de ensino.

\title{
1. ENSINO MÉDIO NO BRASIL: REFORMAR PARA NÃO MUDAR
}

Já em sua origem, nos anos 1930, quando se constituíam os primeiros passos de um sistema público de ensino no país, o ensino médio foi defendido por setores influentes da sociedade brasileira como um "luxo aristocrático" não acessível aos filhos das camadas populares. Tais setores sustentavam a tese de que o ensino médio, de caráter propedêutico, deveria ser oferecido pela iniciativa privada para famílias que pudessem arcar com seu ônus. Como proposta pedagógica, as escolas deveriam se mirar no sistema do liceu francês, que tinha uma perspectiva de formação acadêmica e voltada para as belas artes. (ZIBAS, 2005).

Segundo Nora Krawczky (2014, p. 79):

\begin{abstract}
A polêmica sobre a identidade do ensino médio e se ele deve estar mais voltado para a profissionalização ou para a formação geral, se para a cidadania ou para a universidade, os movimentos constantes de reforma na sua estrutura (passando de uma organização única a uma organização com orientações diversas e vice-versa) e as demandas constantes para inclusão e/ou exclusão de novos conteúdos no currículo são exemplos das tensões em torno desse nível de ensino em diferentes países.
\end{abstract}

De acordo com essa autora, o ensino secundário surgiu no século XX em diferentes países com uma "configuração dual" a partir de uma tensão entre ter como objetivos a formação geral para a cidadania ou a formação específica para a inserção no mercado de trabalho. Assim ele representava uma etapa posterior à formação básica nas habilidades de leitura e cálculo, marcado pela apropriação diferenciada do conhecimento. Para alguns, foco nas habilidades produtivas para o mundo do trabalho; para poucos privilegiados, foco na continuidade e no aprofundamento dos estudos voltados para a apropriação da "cultura erudita", com alto prestígio social.

No caso brasileiro, contribuiu para a consolidação dessa dualidade a criação do Sistema $S$ na década de 1940, que através da parceria com a iniciativa privada foi responsável pela implantação de um sistema de escolas técnicas de nível médio com o objetivo de suprir a formação de mão de obra necessária ao desenvolvimento econômico 
da época. Para os alunos que se aventuravam pela formação técnicoprofissional o caminho terminava aí, uma vez que esse percurso não permitia prestar os exames de acesso ao ensino superior.

Tal estrutura segmentada e extremamente rígida foi criticada por educadores progressistas e movimentos sociais que passaram a denunciar seus efeitos discriminatórios, trazendo como bandeira de lutas o direito a um ensino médio de formação geral para todos. Essa perspectiva democratizante motivou vários movimentos sociais que pressionaram por reformas do ensino médio brasileiro na década de 1960. Assim foi reconhecida a equivalência entre diferentes cursos nesse nível de ensino e definiu-se pelo fim do caráter de terminalidade dos cursos profissionalizantes.

Por outro lado, outras propostas que se orientavam por uma perspectiva conservadora se fizeram presentes, restringindo a mobilidade educacional e impondo a segmentação dos percursos escolares (KRAWCZKY, 2014). Essa foi a orientação da legislação aprovada em 1971 pelo Regime Militar por meio da Lei 5692/71 que instituiu a profissionalização compulsória no antigo segundo grau. Dagmar Zibas (2005, p. 1069) ilustra da seguinte forma esse momento:

Em consonância com o padrão preconizado pelos assessores estrangeiros, Roberto Campos, ministro do Governo Militar, já defendia, em 1968, que o ensino secundário deveria perder suas características de educação humanística e ganhar conteúdos utilitários e práticos, atendendo ao povo (e, evidentemente, às necessidades da produção), ao passo que o ensino superior se destinaria, inevitavelmente, às elites (GHIRALDELLI Jr., 1994). Essa focalização no mercado parecia "cair como uma luva" para a solução do problema criado pela crescente pressão à expansão de vagas nas universidades públicas, pressão exercida, na época, por setores médios até então alijados do ensino superior.

Mesmo com a revogação da sua orientação compulsória em 1982 pela Lei 7.044/82, uma vez que se mostrou ineficaz por falta de investimentos públicos e por não atender às expectativas das famílias dos setores médios, as propostas que se seguiram trazem essa permanente tensão entre uma perspectiva que se orienta pela ideia da formação geral e comum como um direito de todos os estudantes e uma visão que defende princípios de seletividade e segmentação nesse nível de ensino.

Tal tensão, irá se expressar com novos matizes nas polêmicas que se travaram a partir dos anos 1990 em torno da proposta de formação profissional integrada ao ensino médio e nas recentes disputas, em torno de uma proposta de reestruturação desse nível de ensino, contidas tanto no PL 6.840/2013, ${ }^{4}$ quanto na Lei 13.415/17. Como pano de fundo na discussão sobre alguns aspectos de uma proposta curricular 
para o ensino médio permanece visível a disputa entre uma perspectiva democratizante que defende o direito a uma formação geral para todos os jovens brasileiros ou uma posição seletiva que defende a segmentação dos percursos escolares. Quantas e quais disciplinas devem compor o currículo do ensino médio? Como se dá a relação entre formação geral e formação profissional? Como organizar a escola de ensino médio? Em módulos? Em sistemas de crédito? Qual o perfil do profissional que atuará no ensino médio? Como se organizará o ensino noturno? O ensino noturno deverá existir? Tais questões e muitas outras que surgem no atual debate sobre a reforma do ensino médio trazem no seu bojo essa tensão entre universalização e seletividade.

Podemos dizer que vivemos, nos últimos vinte anos, movimentos de avanços e retrocessos nas políticas para esse nível de ensino que estiveram marcadas por essa polarização. Apesar da expansão significativa das matrículas, passando de cerca de 3,7 milhões em 1991 para algo em torno de 10 milhões se considerarmos a EJA (SIMÕES, 2016), tal expansão não foi acompanhada de um efetivo compromisso do Estado com investimentos nas escolas e na valorização dos docentes.

Podemos dizer que isso é resultado, em boa parte, das ambiguidades contidas na LDB 9394/96. Essa lei sofreu grandes interferências das orientações hegemônicas nos anos 1990 na implantação de reformas que se miravam nos princípios de eficácia e eficiência do mercado, apresentando um paradigma de educação com brechas para a manutenção da dualidade estrutural. Expressão disso foi a promulgação da Lei $2.208 / 97^{5}$ que permitiu criar um sistema paralelo de formação técnica organizado em módulos separados do ensino médio regular. Em 2004, o Decreto 5.154/04, ${ }^{6}$ embora sem romper radicalmente com a dualidade, abriu possibilidades para a organização pelos sistemas de ensino de propostas curriculares que integrassem no ensino médio formação geral e ensino técnicoprofissional. Segundo Zibas (2005: p. 1084), naquele momento isso resultou na instituição de três perfis possíveis:

a) a continuação, como no estado de São Paulo, da estrutura dual prescrita pelo Decreto n. 2.208 de 1997; b) algumas experiências, como no estado do Paraná, de implementação da escola unitária e politécnica; c) em outros estados, há possibilidade de reintegração entre o ensino médio e técnico conforme modelo vigente antes da legislação de 1997.

Além disso, acompanhando o espírito das orientações de agências internacionais que priorizaram o investimento no Ensino Fundamental, o Governo FHC atuou para que a lei não incorporasse 
o ensino médio como uma obrigatoriedade. Tal orientação é uma das grandes responsáveis pelo quadro caótico que encontramos com relação às condições materiais e de trabalho nas escolas brasileiras de ensino médio de uma maneira geral, objeto de denúncia do Tribunal de Contas da União. (Brasil/TCU, 2014). Somente a partir de 2007 as escolas contaram com recursos de um fundo específico, o FUNDEB. Da mesma forma, tardiamente o ensino médio foi reconhecido como etapa gratuita e obrigatória por meio da Emenda Constitucional 59 de $2009^{7}$ e incorporada à LDB somente em 2013 pela Lei $12.796 .^{8}$

A massificação do ensino médio, seja na primeira onda expansionistas dos anos 1970 e 1980 ou no crescimento acelerados das matrículas a partir dos anos 1990, não contou assim com o efetivo compromisso do Estado, gerando grandes problemas em relação às condições de atendimento, especialmente nas escolas públicas estaduais, responsáveis por 85\% das matrículas (KRAWCZKY, 2014). Aqui podemos falar de uma segunda dualidade recorrente na história da escola pública no Brasil. Aquela que se estabelece sobre a divisão entre boas escolas (públicas ou privadas) e escolas precárias (públicas ou privadas). Algumas poucas escolas públicas e privadas de alto padrão funcionam como verdadeiros "condomínios fechados do conhecimento escolar", ao lado da maior parte das escolas públicas pauperizadas, que enfrentam muitas dificuldades no seu cotidiano. Tal dualidade instituiu territórios escolares onde os filhos de diferentes classes sociais não se encontram. Escolas para ricos e escolas para pobres!

Deve-se reconhecer que houve um movimento de incorporação de algumas propostas de cunho progressista nas propostas do Governo FHC para o ensino médio, o que permitiu dar legitimidade às suas ações. As DCNEM (Resolução 03/98 do $\mathrm{CNE}$ ), embora se orientem pelas condicionalidades impostas pelas agências internacionais, incorporaram algumas bandeiras do campo progressista. No entanto, segundo Zibas (2005, p. 1073):

(...) tais princípios vêm articulados aos objetivos da pedagogia das competências, a qual, como se sabe, prioriza a construção de um novo profissionalismo (Ramos, s/d.) e de novas subjetividades, centrando-se em esquemas cognitivos e socioafetivos que promovam a constante adaptação e readaptação dos jovens, tanto às mutantes necessidades de produção quanto à redução, dita inexorável, do emprego formal. Nessa abordagem, a responsabilidade pela superação do desemprego e de outras desigualdades sociais fica a cargo exclusivamente do indivíduo, ocultando-se os condicionantes sociais e históricos da conjuntura.

Um segundo aspecto, refere-se à ausência de qualquer proposta em relação à escola noturna, grande responsável por acolher 
a expansão do ensino médio. Segundo Zibas (2005), por trás desse "esquecimento" estava o projeto de restringir a oferta do ensino médio noturno, dirigindo as matrículas para cursos supletivos.

É nesse contexto de um campo de disputas marcado por avanços e retrocessos que compreendo a edição da Lei 13.415/17. Trata-se de mais uma movimentação no jogo de forças dos atores que disputam as orientações para o ensino médio. A pretexto de "flexibilizar" a organização curricular das escolas de ensino médio, torna mais enrijecida e empobrecida a formação oferecida. Como descrito anteriormente, uma das principais mudanças diz respeito à instituição de cinco diferentes percursos formativos (artigo $36 \mathrm{da}$ LDB) "que deverão ser organizados por meio da oferta de diferentes arranjos curriculares, conforme a relevância para o contexto local e a possibilidade dos sistemas de ensino". A impossibilidade de mudar de percurso, além de que a escola não se obrigará a ofertar todos os itinerários para a livre escolha dos alunos, torna-se um problema para adolescentes que, nesse momento da vida, ainda estão construindo seus projetos de futuro e, naturalmente, têm muitas dúvidas sobre isso.

Assim, há flexibilização da oferta para os sistemas de ensino, o que atende à demanda de governadores e gestores estaduais. No entanto, para os jovens estudantes, estreitam-se as possibilidades. Opta-se por uma formação fragmentada em áreas do conhecimento e corre-se o risco de produzir um quadro caótico nas redes como uma resposta à obrigatoriedade legal da universalização do ensino médio. Novamente retrocede-se às concepções reducionistas da formação de nível médio. E mais uma vez a escola noturna é "esquecida". Aquela que atende preferencialmente aos jovens das camadas populares é tratada como uma escola que oferece um ensino de segunda categoria.

Uma das principais críticas à proposta refere-se ao caráter autoritário, sem discussão ampla com a sociedade sobre a medida (FaE-UFMG, 2016). Essa é outra recorrência na história das reformas educacionais no Brasil. Elas têm sido pensadas como projetos que se destinam aos "outros". Nesse caso, professores e jovens das camadas populares, sempre pensados como destinatários das políticas públicas em geral e nunca como atores com direito à participação na sua formulação.

Miguel Arroyo, em um instigante texto intitulado "Repensar o Ensino Médio: Por quê?” (ARROYO, 2014) nos chama a atenção para esse traço em relação às reformas educacionais. De uma maneira geral são reformas que pretendem "inovar pelo alto" através de medidas que visam "ilustrar" a melhor forma de educar, "normatizar" os processos educativos e "persuadir" os educadores de que esses 
processos são válidos e necessários. Novamente: urgentes! Não porque seja uma urgência social, como preconizava Moll e Garcia (2014), mas como pretexto para a interdição do debate, para que os "outros" não possam se manifestar.

Experiências similares foram implantadas em Minas Gerais e Pernambuco. Em Minas Gerais, além da tentativa frustrada de implantar a organização por áreas nas duas últimas séries do ensino médio em meados dos anos 2000, ${ }^{9}$ a Secretaria Estadual de Educação desenvolveu a partir de 2012 um programa intitulado Reinventando o Ensino Médio. ${ }^{10}$ Inicialmente como uma experiência piloto, ele foi universalizada em 2014. Teve como foco a reformulação curricular da rede estadual de ensino, acrescentando ao Currículo Básico Comum (CBC) da rede estadual, conteúdos de qualificação profissional reunidos em dezoito áreas de empregabilidade. A proposta supunha a ampliação da carga horária para 3.000 horas anuais e esperava proporcionar uma formação que possibilitasse a inserção na educação superior e/ou no mercado de trabalho.

Um dos limites das experiências-pilotos é o fato de não supor um processo contínuo de construção e mobilização das redes de ensino. Depois de construídas em contextos ideais produzidos para o seu sucesso, as experiências tornam-se modelos a serem aplicados a qualquer contexto. Além de uma orientação fundamentada no paradigma da empregabilidade, esse movimento vindo de cima para baixo, sem a intervenção nas condições de funcionamento das escolas, gerou vários conflitos e dificuldades nas escolas, como registram depoimentos de diretores e docentes. Quais os efeitos dessas medidas? Foram capazes de superar os dilemas do ensino médio mineiro? Foram capazes de melhorar o IDEB, foco dessas mudanças?

O Governo de Pernambuco implantou, no sistema de ensino estadual a partir de 2008, as Escolas de Referência em Ensino Médio de Pernambuco (EREMs) dentro do Programa de Educação Integral (PEI). A proposta envolvia um terço das escolas de ensino médio, mas boa parte delas atendia a outros níveis de ensino e mais da metade implantou o ensino médio em tempo semi-integral. Um aspecto central na proposta foi a instituição de uma política de responsabilização dos docentes e gestores pelas metas a serem alcançadas, especialmente em relação ao fluxo escolar e à melhoria dos índices nas avaliações sistêmicas. Para isso foi instituído um sistema de bonificações chamado Bônus de Desempenho Educacional - BED. Paralelamente, foram implantadas também telessalas para alunos do ensino médio com defasagem idade/série por meio de convênios 
com as Fundações Ayrton Senna e Roberto Marinho. Apesar da correção no fluxo escolar e na melhora nos índices gerais do IDEB, o desempenho em português e matemática permaneceu muito baixo. Além disso, instituiu-se uma desigualdade grande entre as condições de trabalho e salariais dos professores. (SILVA e SILVA, 2014).

Em seu texto, Arroyo (2014) parte da ideia de que o ensino médio já está sendo reinventado cotidianamente por docentes e estudantes, nas várias experiências desenvolvidas em suas escolas. Essas experiências são inovadoras porque os atores - docentes e jovens estudantes também são novos. Tanto os jovens que chegaram ao ensino médio nos últimos vinte anos são outros, em termos de origem social, raça, territórios, orientações sexuais etc., como também o perfil e a relação dos professores com a docência se alterou muito nesse período.

O desafio para as políticas públicas está então em apoiar e reconhecer as práticas inovadoras que esses sujeitos constroem. Essa orientação, reconhecida pela LDB 9394/1996 e pelas DCNs da Educação Básica e do Ensino Médio quando definem que professores e alunos são autores e atores do PPP das escolas, tem sido constantemente negada e se repete agora com o processo em curso de reestruturação do ensino médio. Isso se agrava ainda mais porque a capacidade de inovação também tem sido limitada pelas condições objetivas - infraestrutura precária, excesso de trabalho, ausência de tempos coletivos - e subjetivas - insegurança, incerteza, desmotivação. Além disso, é preciso reconhecer que as condições de vida dos docentes, estudantes e suas famílias impõem também limites à participação e muitas vezes levam ao abandono, à acomodação e à postura pouco crítica em relação à escola. Sem considerar as condições objetivas e materiais dos atores e das escolas, o discurso da participação se constitui como uma política de transferência de responsabilidade.

Outro aspecto no que tange à Lei 13.415/17 diz respeito ao papel do ensino médio no atual cenário produtivo. Se o projeto de desenvolvimento da Ditadura Militar teve como um dos eixos a formação profissional compulsória, essa relação toma novos contornos desde os anos 1990. A pressão hoje parece ser no sentido de adequar o ensino médio às demandas e contradições postas pelo novo padrão de desenvolvimento global marcado pela centralidade das tecnologias da informação. O desenvolvimento das TIs impactou a vida cotidiana e as formas de produção de uma maneira muito grande. As crianças nascem e se socializam como "nativos" digitais. Os jovens se deparam com exigências de novos conhecimentos no mercado de trabalho volátil - trabalhar em equipe, ser criativo e 
inovador, ser empreendedor - ao mesmo tempo em que as tarefas se tornaram mais simples e flexíveis. Como consequência, a vida laboral se tornou mais incerta e imprevisível. Em nossas pesquisas ouvimos sempre de jovens e pais que "até para ser gari tem que ter ensino médio". Formação mínima, mas não suficiente num quadro em que a demanda por emprego aumenta entre os jovens. Esse quadro tem gerado uma corrida crescente em relação à certificação escolar, com um aumento da competição por um posto de trabalho.

Por fim, o processo apressado de discussão e aprovação da Lei 13.415/17 desconsiderou políticas anteriores que se constituíram a partir do acúmulo feito em debates com a sociedade, educadores, jovens e pesquisadores sobre o ensino médio brasileiro. Como exemplo pode-se citar o Programa Ensino Médio Inovador ProEMI. ${ }^{11}$ Lançado em 2009 como programa experimental, o ProEMI do último ano do Governo Lula e da gestão Dilma tinha como foco induzir inovações curriculares em escolas por meio de regime de cooperação com as secretarias estaduais. Tratava-se de um programa de apoio às inovações pedagógicas, por meio de transferência de recursos financeiros para projetos propostos pelos docentes e ações de formação em serviço. Além de fomentar as práticas inovadoras, a proposta supunha a expansão da carga horária em mais 600 horas anuais. Teve como eixos aspectos que iam além de mudanças curriculares, prevendo o apoio à gestão do sistema e das escolas, a melhoria da infraestrutura escolar, a formação continuada, a valorização do trabalho docente, a participação juvenil nas escolas e o fomento a pesquisas sobre esse nível de ensino. Apesar de uma abrangência ainda modesta, a proposta supunha dar flexibilidade e autonomia às escolas para, a partir de alguns eixos estruturadores, elaborarem suas propostas, o que permitia melhores oportunidades para acumular experiências e fomentar reflexões tendo docentes e jovens como protagonistas. Porque não investir nessa direção, partindo do chão da escola para construir inovações curriculares?

\section{O QUE OS JOVENS TÊM A NOS DIZER?}

De uma maneira geral, as propostas de reformas do ensino médio trazem como argumentos centrais a necessidade de atender às "novas" demandas do setor produtivo ou a necessidade de melhorar nossa posição no ranking dos sistemas de avaliação. Embora no bojo delas estejam subjacentes concepções sobre os educandos e sobre a educação considerada mais adequada a eles, pouco se atenta para as experiências 
deles e para as suas demandas. Talvez um bom ponto de partida nas análises das propostas em voga seja nos perguntarmos sobre como concebem os sujeitos ao qual se destina esse nível de ensino. Quem são os jovens estudantes das escolas públicas de ensino médio brasileiro? São os mesmos de 20 ou 30 anos atrás? Qual nosso olhar sobre esses sujeitos? O que conhecemos da condição juvenil brasileira contemporânea?

Um primeiro aspecto a considerar no debate sobre os rumos do ensino médio se refere às repercussões das transformações sociais sobre a condição juvenil brasileira que incidem diretamente sobre suas experiências escolares. A relação estabelecida com a instituição escolar e com a escolarização mudou nos últimos anos, fruto de novos processos de socialização das novas gerações. (SETTON, 2005; DAYRELL, 2007). Algumas experiências nos últimos anos buscaram compreender tal processo escutando os jovens por meio de pesquisas, rodas de conversas, oficinas ${ }^{12}$ (CORTI, FREITAS e SPOSITO, 2001; DAYRELL e JESUS, 2013; CORTI e SOUZA, 2009).

Tais experiências evidenciaram de maneira muito contundente os efeitos do processo de massificação no contexto das transformações acima citadas. As políticas de focalização no Ensino Fundamental que, aliados às pressões sociais e do mercado de trabalho pela "busca pelo diploma”, geraram uma acelerada expansão das matrículas no ensino médio brasileiro a partir dos anos 1990 (CORTI, 2016). Sem dúvidas, tal fenômeno desencadeou uma maior inclusão, uma onda democratizante em termos de acesso. Mas, por outro lado, trouxeram novos dilemas e desafios dados por traços de uma inclusão precária e parcial. Embora tenha aumentado os níveis de aprovação, as taxas de evasão e retenção ainda continuam altas. Se considerarmos a taxa líquida de matrículas temos que apenas $51 \%$ dos jovens de 15 a 17 anos frequentam hoje o ensino médio. Os restantes estão ainda no Ensino Fundamental (34\%) ou fora da escola (KRAWCZKY, 2014).

Para além desses dados absolutos sobre a expansão do acesso, cabe perguntar: o que significou essa chegada massiva de novos sujeitos nas escolas - negros, trabalhadores, moradores das periferias? Que implicações isso tem para a experiência cotidiana de jovens e educadores? A chegada desses novos atores alterou o perfil dos estudantes, trazendo para a escola questões que expõe, mas contradições de nosso sistema educacional. Eles encontraram uma escola enrijecida, pouco preparada para lidar com um perfil de estudante que foge ao padrão do "aluno ideal". Esses estudantes chegam às instituições escolares com toda a sua humanidade - saberes, experiências culturais, modos de ser - e 
com suas desumanidades, produzidas pelas estruturas sociais desiguais de nossa sociedade - desemprego, formação escolar precária, vivência de situações de violência, racismo e sexismo. É esse jovem concreto que chega à velha escola "republicana" e que a questiona em sua experiência cotidiana como estudante.

Instala-se então uma tensão crescente na instituição escolar. Submetidas aos processos de socialização contemporâneos, as novas gerações desenvolvem modos de ser que não correspondem diretamente ao modelo escolar da modernidade - racional, planejada, previsível. Tal tensão impacta especialmente a relação dos jovens com seus professores. Talvez por isso as pesquisas educacionais cada vez mais tendam a incorporar categorias como "alunos difíceis" ou "alunos problemas", como nos lembra Agnés Van Zanten (2008) ao falar dos processos de socialização profissional dos docentes das escolas da periferia parisiense. A relação dos jovens com a escola pública torna-se cada vez mais tensa e ser professor nessas condições constitui-se numa tarefa muitas vezes desgastante.

Quantas vezes não ouvimos manifestações saudosistas dos professores sobre "os alunos de antigamente"? É comum ouvir os professores reclamarem dos "alunos incivilizados" que não respeitam as regras escolares, que não cumprem suas atividades, que conversam durante a aula, usam celulares etc. As relações de autoridade tornam-se um problema central a ser administrado e que ocupa grande parte do tempo escolar. "Esses jovens vão para a escola, mas não querem nada com os estudos", dizem os professores. Seria isso mesmo? Os jovens não querem nada com a escola? Porque acorrem cotidianamente a ela? Porque, então, em seus depoimentos para nossas pesquisas falam da grande importância da educação hoje? Estariam eles nos ludibriando?

Parece que o ofício de aluno constitui-se cada vez mais como uma experiência ambígua para os jovens contemporâneos. Em um cenário em que ter o diploma abre maiores possibilidades de inserção social e profissional, cumprir sua trajetória escolar com um mínimo de regularidade se torna uma imposição. Ao mesmo tempo, ele deve adequar-se à vida escolar em uma instituição pouco permeável às experiências sociais e culturais da sua vida, que de um lado exige um grande esforço e de outro escancara a falta de sentido de muitos conteúdos. A resposta de muitos estudantes está em assumir a atitude de uma distância administrada em relação aos professores e às tarefas escolares. Um colocar-se num entrelugar. Estar e não estar na escola, ser e não ser aluno. Tal atitude tende a ser vista como uma afronta pelos docentes, transformada muitas vezes em um conflito de ordem pessoal ou um questionamento de sua autoridade. 
O discurso da "crise do ensino médio" e da urgência de sua reforma muitas vezes parte de visões fatalistas sobre esse cenário. Baixos índices no IDEB, evasão e retenção, falta de sentido, indisciplina, violência etc. Identificados os problemas, passa-se à busca dos "culpados". É quando jovens, pais, docentes e gestores entram em desacordo, desenvolvendo um "diálogo de surdos". É preciso exercitar a escuta e o olhar para compreender os dilemas e impasses a serem enfrentados. Como refletir sobre tais tensões sem que os sistemas de ensino organizem tempos para os professores discutirem coletivamente esses problemas? Como construir relações de autoridade sem espaços democráticos de interlocução com os estudantes? Como reestruturar a escola sem a participação dos atores nela envolvidos?

Uma grande dificuldade tem sido reconhecer os jovens como atores no processo de elaboração e implantação das políticas públicas. No caso das propostas de reestruturação do ensino médio brasileiro, isso se traduz na absoluta falta de espaços para que os estudantes possam se manifestar. Como exemplo, pode-se citar o movimento de ocupações das escolas por secundaristas em 2015 contra o projeto de reorganização escolar do Governo do Estado de São Paulo que pretendia fechar 94 escolas, centenas de turmas e realocar os estudantes em outras unidades escolares. (CAMPOS, MEDEIROS e RIBEIRO, 2016).

Esse tipo de postura que invalida e silencia a voz dos jovens se sustenta a partir de compreensões limitadas sobre a juventude que a reduzem a uma mera fase de imaturidade, problemática e transitória. No cotidiano escolar esse imaginário se apresenta constantemente. "Quando você for adulto poderá entender isso!"; "Eu já passei por isso, sei do que estou falando!"; "Eu já estou com a vida ganha, vocês é que precisam se esforçar agora!" são falas repetidas inúmeras vezes por nós em nossos (des)encontros com adolescentes. Nessa visão, a juventude é um momento que se justifica apenas pelo que "virá a ser" e não pelas experiências vividas agora. Passageiros, os jovens teriam pouco a dizer sobre o ensino médio, uma vez que não são reconhecidos como sujeitos de direitos, cidadãos com capacidade para opinar e decidir sobre os rumos das escolas.

Outras visões tendem a romantizar e a idealizar a juventude como naturalmente revolucionária e inovadora, muitas vezes a partir de imagens como os jovens revolucionários dos anos 1960 ou os "caras pintadas" dos anos 1980. Ou a encará-la como um "modelo cultural" a ser perseguido (PERALVA, 1997). Da mesma forma, essas visões romantizadas rapidamente se convertem em olhar negativo quando eles não aderem automaticamente a propostas de participação na escola. "Consumistas e alienados", dizem alguns. 
Infelizmente, esses olhares negativos muitas vezes contaminam a relação de docentes e estudantes, impedindo desenvolver uma compreensão sobre os jovens concretos que habitam nossas escolas. Contaminam também as políticas públicas, que geralmente partem de uma visão negativa sobre o público a que se destinam: "os jovens como um problema social" e "potencial ameaça para a sociedade e suas instituições".

Por isso alguns estudos chamam a atenção para a categoria condição juvenil. Nessa perspectiva os jovens são sujeitos históricosociais, produtos e produtores de um tempo, diversos em suas experiências assim como são diversas as identidades e espaços sociais de uma determinada sociedade. A condição juvenil compreende tanto as condições objetivas e estruturais que configuram as oportunidades e limites da vivência dessa fase da vida, quanto às representações sociais e ao modo como cada sociedade em diferentes épocas e contextos trata esses sujeitos, definindo seus direitos e obrigações (ABRAMO, 2005; DAYRELL, 2007).

Há traços comuns dessa fase da vida: transformações de ordem psíquica, biológica e social; construção de projetos de futuro; abertura para novas experiências e relações afetivas, etc. Mas há aspectos que são característicos de determinados pertencimentos de gênero, raciais, territoriais etc. - e contextos sociais - urbanos, rurais, indígenas etc. Podemos dizer que a diversidade é uma marca da condição juvenil contemporânea e o seu reconhecimento deve ser base para qualquer projeto pedagógico no ensino médio. Se as diferenças produzem tensões no cotidiano escolar, o seu silenciamento e a negação do direito à diferença significam reforçar a já tensa relação da juventude com a escola.

Esse é um ponto central, tendo em vista que alguns projetos em tramitação em diferentes níveis na linha do Movimento Escola sem Partido $^{13}$ tendem a impedir que determinados temas sejam discutidos no ambiente escolar. Muitas dificuldades que as escolas enfrentam na relação com a juventude se referem exatamente à resistência em compreender e reconhecer tais diferenças, ancoradas ainda que estamos, em uma visão homogeneizante do currículo e da escola. Mais uma vez, lembrando Arroyo (2014), uma escola pensada a partir de nós - brancos, heterossexuais, classe média, racionais para outros que chegam agora no ensino médio- negros, indígenas, quilombolas, LGBTTs. São coletivos que têm o direito a serem reconhecidos em suas diferenças, como já preveem as Diretrizes Curriculares Nacionais do Ensino Médio. Jovens estudantes que têm o direito a "se saberem"! (ARROYO, 2014). 
Além de sua diversidade, a condição juvenil brasileira está marcada pela experiência das desigualdades sociais. Esse é um aspecto fundamental que incide sobre a relação dos jovens com o ensino médio. Em um cenário de incertezas e imprevisibilidades, nesses "tempos líquidos" como diz Zygmunt Bauman (2007), os jovens são chamados a construir seus projetos de futuro e a assumirem a responsabilidade por suas escolhas num horizonte restrito de possibilidades. No banquete da globalização, o menu é extenso para alguns poucos e mínimo para muitos.

Temos hoje no Brasil em torno de 51 milhões de pessoas entre 15 e 29 anos, segundo o Censo Demográfico de 2010. A grande maioria desses jovens (85\%) mora em zonas urbanas. Grande parte deles jovens são filhos de famílias com baixo poder aquisitivo (menos de um salário mínimo per capita) e dependem do trabalho como possibilidade para estudar, comprar bens de consumo juvenis, namorar etc. Esses jovens, muitas vezes veem seus percursos de vida interrompidos precocemente pela incidência da violência que atinge sobremaneira os jovens negros do sexo masculino (DAYRELL e CARRANO, 2014). Essa é a realidade da maior parte dos jovens das escolas públicas de ensino médio. Jovens que têm limitadas oportunidades de vivência das suas experiências e de construção de seus sonhos e projetos futuros. São esses jovens concretos que nos interrogam sobre o ensino médio que queremos! Não tem sentido pensar conteúdos, formas de organização, tempos, espaços e processos avaliativos sem compreender e reconhecer suas demandas, necessidades e especificidades. O que esses jovens têm a nos dizer?

Como ditos anteriormente, diversos estudos e experiências permitem reunir elementos para responder a tais questões. Sem desconhecer a importância de várias pesquisas, sobre o ensino médio, já concluídas ou em andamento que abordam a relação entre ensino médio e condição juvenil, ${ }^{14}$ iremos nos concentrar em dois estudos desenvolvidos no âmbito do Observatório da Juventude da UFMG que nos trazem importantes elementos para problematizar a escola de ensino médio da perspectiva dos jovens e suas demandas. Uma pesquisa nacional realizada em 2005 pelo IBASE e o Instituto Pólis, da qual esse grupo de pesquisa participou como parceiro, sobre os limites e possibilidades da participação juvenil aplicou 8.000 questionários e ouviu 913 jovens em grupos de discussões em sete regiões metropolitanas e no Distrito Federal. Perguntados sobre o que esperavam na área da educação, por ordem de frequência, os jovens assim responderam: 
1 - Expansão do ensino médio; 2 - Mais professores(as) nas escolas; 3 Professores(as) mais qualificados(as) e melhor remunerados(as); 4 - Melhores currículos, metodologias, material didático e mais atividades extras (passeios, visitas, palestras, laboratórios); 5 -Mais verbas/investimentos para a educação; 6 - Melhores condições de funcionamento das escolas/Preservação das escolas; 7 - Mais ofertas de cursos profissionalizantes de qualidade. (IBASE; POLIS: 2005, p. 23).

Esses dados revelaram já naquele momento a consciência dos jovens sobre as condições precárias da educação que lhes é oferecida, que se traduzem em demandas por uma escola com o mínimo de qualidade e oportunidades. Ficou patente também na pesquisa a demanda dos jovens pela criação nas escolas de canais de participação juvenil e como elas estavam distantes de oferecerem esse tipo de experiência (DAYRELL, GOMES e LEÃO, 2010). Em geral, a abordagem com relação ao tema prioriza a "formação para a cidadania" e não a formação no exercício da cidadania, o que supõe reconhecer e valorizar os espaços institucionais e não institucionais da cidade nos quais os jovens já se inserem como sujeitos políticos e de direitos.

Uma segunda pesquisa, realizada em 2009 e intitulada "Diálogos com o Ensino Médio", buscou compreender o lugar da escola de ensino médio na construção dos projetos de vida dos jovens estudantes no estado do Pará. Foram ouvidos 245 jovens em grupos de discussão com estudantes de diferentes idades e contextos sociais, oriundos de escolas de três municípios paraenses (LEÃO, DAYRELL e REIS, 2011).

Também nessa pesquisa o mito dos "jovens contra a escola" foi desconstruído. Nos vários encontros promovidos, mais uma vez desvelou-se a negligência das políticas públicas com relação ao ensino médio por meio dos depoimentos que indicavam vários problemas de ordem material e de gestão. Apesar disso, a escola ocupava uma centralidade grande como condição para a efetivação de projetos futuros, às vezes de uma forma superdimensionada. A maior parte deles teve muitas dificuldades para relativizar a capacidade da escola como instrumento de mobilidade social.

De modo especial, ficou patente o papel dos educadores como referência na construção de projetos futuros. Para além da imagem de escolas em crise do ponto de vista das relações entre professores e alunos, os jovens tendiam a manifestar visões positivas dos docentes. Por outro lado, se ressentiam de uma escola que não tem altas expectativas em relação ao futuro deles. Para eles, a falta de investimento dos professores e gestores escolares era uma manifestação de que a escola não acreditava em suas potencialidades, fato constatado também em outras pesquisas (KRAWCZKY, 2014). 
Essa situação, muitas vezes se traduz em um paradoxo. É comum que os jovens estudantes critiquem a falta de sentido do conhecimento escolar, a rigidez e pouca atratividade da escola. Por outro lado, gostam e demandam que os professores sejam mais exigentes e comprometidos e que a escola ofereça mais conteúdos que os preparem para vestibulares e concursos. $\mathrm{Na}$ ausência de experiências inovadoras, muitas vezes os estudantes apelam para os tradicionais modelos de escolarização que conhecem, culpando-se uns aos outros pela indisciplina e falta de compromisso com o ofício de aluno.

Tal paradoxo somente pode ser compreendido se atentarmos para o processo da expansão do ensino médio brasileiro em um contexto de crise social e acirramento das desigualdades. (SPOSITO, 2005). A chegada de jovens das camadas populares, grande parte trabalhadores ou desempregados e filhos de pais menos escolarizados na escola pública de ensino médio traz para ela demandas e expectativas que não se traduzem automaticamente em investimento e comprometimento pessoal. Além disso, a reprodução da pobreza e das desigualdades incide diretamente sobre a experiência escolar. Para muitos jovens as demandas por condições básicas de vida são prioritárias em relação aos estudos.

Outro aspecto citado por esses jovens referia-se à ausência de um diálogo maior com diretores escolares, especialmente no turno da noite. Estabeleceu-se uma comparação entre escolas em que a direção escolar se fazia presente e dialogava com os estudantes e outras escolas onde gestores e estudantes se desconheciam. Sabemos como tem sido difícil cumprir com as muitas exigências em relação à descentralização administrativa e à autonomia escolar. Diretores e docentes encontram-se assoberbados de atividades relativas à gestão financeira, à administração e à coordenação de projetos. Isso gera uma grande dificuldade para construir tempos coletivos de estudo, planejamento e tomada de decisões e para acompanhar e orientar a vida escolar de um número excessivo de alunos. Tal constatação não significava um desconhecimento dessa realidade. Pelo contrário, em geral os estudantes são sensíveis e tendem a se solidarizar com os educadores em relação às suas condições de trabalho. A questão se referia à construção de relações horizontais com a gestão escolar, onde pudessem expressar suas inseguranças e apresentar suas demandas, onde se sentissem acolhidos e valorizados.

\section{CONSIDERACְÕES FINAIS}

Esse texto reuniu reflexões sobre alguns traços do ensino médio brasileiro que foram se constituindo ao longo de sua trajetória. Ele não teve 
a preocupação em produzir uma narrativa linear, mas indicar algumas das que considero as principais tensões dessa "tardia, desigual e insuficiente" história das políticas para o ensino médio no Brasil. Um percurso feito de idas e vindas, contradições, incoerências e inconsistências.

Os depoimentos dos jovens, reunidos a partir de pesquisas e de nosso contato cotidiano nas escolas, nos permitem perceber como são grandes os desafios para a escola do ensino médio brasileiro. As reformas propostas darão conta desses desafios? Elas permitirão construir processos educativos que sejam suportes para projetos de futuro dos jovens pobres? Elas permitirão que professores e gestores se constituam em referências positivas nas trajetórias juvenis?

Em relação à Lei 13.415/17 muitas questões se apresentam. A primeira delas se refere ao próprio processo de discussão e aprovação da lei, sem qualquer consulta aos jovens e suas famílias. Nesse sentido, as possibilidades de uma grande dissonância entre as expectativas dos estudantes e os efeitos da lei são grandes.

Outro aspecto importante diz respeito à proposta de "flexibilização" contida na lei. Há uma apropriação equivocada da crítica à rigidez, que jovens e docentes fazem à organização curricular no ensino médio, em nome de um paradigma de flexibilidade sintonizado com o mercado. Os estudos sobre a condição juvenil contemporânea chamam a atenção para as dificuldades dos jovens na construção de suas trajetórias em contextos de incertezas e desigualdades sociais, quase sempre sem contar com o apoio de políticas públicas. A escola de ensino médio pode ser um espaço importante de acolhimento e de acesso a conhecimentos, saberes e experiências que permitam superar tais dificuldades. No entanto, ao propor a construção de propostas curriculares esfaceladas em áreas de conhecimento e com visões tão restritas da articulação entre ensino técnico-profissional e ensino médio, a lei certamente contribuirá para restringir o campo de possibilidades já tão estreito para a maior parte dos estudantes das escolas públicas brasileiras.

É necessário atentar também para o fato de que grande parte dos jovens estudantes do ensino médio brasileiro trabalha e somente pode frequentar escolas noturnas. No entanto, a lei é lacônica a esse respeito, sem prever garantias de acesso à escola noturna em condições adequadas. Assim, ela poderá contribuir para aumentar a evasão e impedir que o extenso número de jovens que hoje não frequenta o ensino médio possa concluir sua escolarização básica.

Nas últimas décadas, fruto da ampliação das matrículas no ensino médio e das políticas de expansão do acesso ao ensino superior, 
as novas gerações passaram a ter como horizonte a formação nesse nível de ensino. A lei, ao criar itinerários formativos desvinculados da formação técnico-profissional, tem explicitamente a intenção de conter tal demanda. Trata-se de um retrocesso que não dialoga com as expectativas juvenis, tendo um impacto negativo especialmente entre os jovens das escolas públicas.

Assim, a atual proposta parece ser herdeira dos impasses e dilemas que marcam a trajetória do ensino médio brasileiro. Qual herança nos reservou essa história? Um ensino médio que nasce e permanece desigual, com uma "configuração dual", seletiva e segmentada. Dual em termos da formação oferecida e também do ponto de vista das condições de funcionamento. Uma escola distante da realidade sociocultural de nosso tempo, incapaz de dialogar com os "jovens concretos" do ponto de vista dos conhecimentos que aborda e da sua didática. E como consequência, uma escola onde construir o sentido para estudar é cada vez mais difícil para os jovens estudantes das camadas populares. Uma escola onde lecionar é um duro e desafiante trabalho.

Mas também uma escola para onde acorrem cotidianamente milhões de jovens. Uma escola que se produz nos encontros e desencontros entre educadores e jovens estudantes. Encontros muitas vezes tensos, mas sempre marcados por emoção porque são encontros entre humanos. Em seu labor cotidiano, para além das dificuldades, docentes constroem experiências significativas. Nesses encontros e desencontros, se formam como educadores e constroem a escola que temos. É em busca dessa escola concreta - com seus erros e acertos - que nossas pesquisas podem nos ajudar.

A condição juvenil interroga a proposta de reforma em debate. Isso exige enfrentar com coragem o desafio de reconhecer as demandas juvenis na definição dos rumos do ensino médio brasileiro! Não se iludir com requentadas receitas curriculares, vindas do alto e que não rompem a lógica seletiva e excludente da educação brasileira. Apenas transferem para professores, estudantes e escolas a responsabilidade pelo seu sucesso ou fracasso.

Não se trata de "partir do zero", desconsiderando as experiências acumuladas e que fazem a escola que temos. Algumas políticas que se constituíram recentemente, mesmo com suas contradições e insuficiências, indicavam o rumo de um longo processo de inovações a partir das escolas e da interlocução com a sociedade. Independentemente dos governos e suas políticas, ou apesar deles, há uma escola de ensino médio sendo produzida por docentes e estudantes em suas escolas. Olhemos em nossas pesquisas e debates para esses processos de construção da escola que temos! Seus alcances e limites! 


\section{REFERÊNCIAS}

ABRAMO, H. W. "Condição juvenil no Brasil contemporâneo". In: ABRAMO, H. W. ; BRANCO, P. P. M. Retratos da Juventude Brasileira: Análises de uma pesquisa nacional. São Paulo: Instituto Cidadania; Editora Fundação Perseu Abramo: 2005.

ARroyo, M. G. "Repensar o Ensino Médio: Por quê?” DAYRELL, J. ; CARRANO, P.; MAIA, C. L. Juventude e Ensino Médio: sujeitos e currículos em diálogo. Belo Horizonte: Editora UFMG, 2014.

BAUMAN, Z. Tempo Líquidos. Rio de Janeiro: Jorge Zahar Editor, 2007.

BRASIL, Tribunal de Contas da União - TCU. Relatório de Auditoria (Fiscalização $\mathbf{n}^{\mathbf{o}}$ 177/2013), Secretaria de Controle Externo da Educação, da Cultura e do Desporto (Secex Educação), Brasília, 2014.

CAMPOS, A. M.; MEDEIROS, J. ; RIBEIRO, M. M. Escolas em luta. São Paulo: Veneta, 352 p., 2016. (Coleção Baderna).

CORTI, A. P.; FREITAS, M. V.; SPOSITO, M. O encontro das culturas juvenis com a escola. São Paulo: Ação Educativa, 2001.

CORTI, A. P.; SOUZA, R. Que ensino médio queremos? Relatório final. Pesquisa quantitativa e grupos de diálogo sobre ensino médio. São Paulo: Ação Educativa, 2009.

CORTI, A. P. Ensino Médio em São Paulo: a expansão das matrículas nos anos 1990.

Educação \& Realidade, Porto Alegre, v. 41, n. 1, p. 41-68, jan./mar. 2016.

DAYRELL, J. "A escola faz as juventudes? Reflexões em torno da socialização juvenill, Revista Educação e Sociedade, v. 28, n.100 - Especial, p. 1105-1128, out. 2007.

DAYRELL, J. ; CARRANO, P. "Juventude e Ensino Médio: quem é esse aluno que chega à escola?” DAYRELL, J.; CARRANO, P.; MAIA, C. L. Juventude e Ensino Médio: sujeitos e currículos em diálogo. Belo Horizonte: Editora UFMG, 2014.

DAYRELL, J. ; GOMES, N. L.; LEÃO, G. Escola e participação juvenil: é possível esse diálogo? Educar em Revista, Curitiba, Brasil, Editora UFPR, n. 38, p. 237-252, set./dez. 2010.

FACULDADE DE EDUCAÇÃO DA UFMG. Texto para discussão - Reforma do Ensino Médio - MP 746/2016. Belo Horizonte: Faculdade de Educação da UFMG, 2016.

FANFANI, E. T. (org.) La escolarización de los adolescentes: desafios culturales, pedagógicos y de política educativa. Buenos Aires: Instituto Internacional de Planeamiento de la Educación IIPE - Unesco, 2012.

IBASE. Juventude brasileira e democracia: participação, esferas e políticas públicas. Relatório Global. Rio de Janeiro: Ibase e Polis, janeiro de 2006.

KRAWCZKY, N. "Uma roda de conversa sobre os desafios do ensino médio." DAYRELL, J. ; CARRANO, P.; MAIA, C. L. Juventude e Ensino Médio: sujeitos e currículos em diálogo. Belo Horizonte: Editora UFMG, 2014.

DAYRELL, J. T.; JESUS, R. E. “A exclusão de jovens adolescentes de 15 a 17 anos no ensino médio no Brasil: desafios e perspectivas.” Relatório de Pesquisa. UNICEF/MEC, 2012. Disponível em: http://observatoriodajuventude.ufmg.br/publication/view/juventudeensino-medio-e-os-processos-de-exclusao-escolar/. Acesso em: 01 fev. 2017.

LEÃO, G.; DAYRELL, J. T.; REIS, J. B. "Jovens olhares sobre a escola do ensino médio." Cad. Cedes, Campinas, vol. 31, n. 84, p. 253-273, mai.-ago., 2011.

MOLL, J. ; GARCIA, S. "Prefácio". DAYRELL, J. ; CARRANO, P.; MAIA, C. L. Juventude e Ensino Médio: sujeitos e currículos em diálogo. Belo Horizonte: Editora UFMG, 2014. 
PERALVA. “O jovem como modelo cultural.” Revista Brasileira de Educação, São Paulo, n. 5/6, p. 15-24, mai./ago., 1997.

SETTON, M. da G. J. "A particularidade do processo de socialização contemporâneo". Tempo Social, v. 17, n. 2. p. 335-350, nov., 2005.

SILVA, K. N. P.; SILVA, J. A. de A. da. "Accountability e intensificação do trabalho docente no Ensino Médio Integral de Pernambuco.” Práxis Educativa, Ponta Grossa, v. 9, n. 1, p. 117-140, jan./jun. 2014

SILVA, M. R. da; OLIVEIRA, R. G. de. (org.) Juventude e ensino médio: sentidos e significados da experiência escolar. Curitiba: UFPR/Setor de Educação, 2016.

SIMÕES, C. A.. "Vozes dissonantes na reforma do ensino médio". Disponível em: https://goo.gl/U1SIHA, Acesso em: 14 out. 2016.

SPOSITO, M. P. Algumas reflexões e muitas indagações sobre as relações entre juventude e escola no Brasil. ABRAMO, H. W.; BRANCO, P. P. M. Retratos da juventude brasileira: análises de uma pesquisa nacional. São Paulo: Instituto Cidadania; Fundação Perseu Abramo, p. 87-128, 2005.

VAN ZANTEN, A. "A influência das normas de estabelecimento na socialização profissional dos professores: o caso dos professores dos colégios periféricos franceses.” In: TARDIF, M. e LESSARD, C. Ofício de professor: história, perspectivas e desafios internacionais. Petrópolis: Vozes, 2008.

ZIBAS, D. M. L. "Refundar o Ensino Médio? Alguns antecedentes e atuais desdobramentos das políticas dos anos de 1990". Educ. Soc., Campinas, v. 26, n. 92, p. 1067-1086, Especial - Out. 2005

\section{NOTAS}

${ }^{1}$ A primeira versão desse ensaio foi produzida para a conferência de abertura do III Seminário Nacional de Gestão e Avaliação em Educação: as políticas educacionais hoje, evento promovido pelo Programa de Pós-Graduação em Gestão e Avaliação da Educação Pública da Universidade Federal de Juiz de Fora, entre os dias 18 e 22 de janeiro de 2017. No momento de sua elaboração, a proposta de reforma do ensino médio (MP 746/16) estava em tramitação no Congresso Nacional, tendo sido concluída em fevereiro de 2017 e promulgada como Lei 13.415/17.

${ }^{2}$ Grifos das autoras.

${ }^{3}$ A esse respeito, a Revista Educação e Sociedade (vol.38, n.139, abr./jun. 2017) produziu recentemente um dossiê com vários artigos sobre o tema. Disponível em: $<$ http://www. scielo.br/scielo.php?script=sci_issuetoc\&pid $=0101-733020170002 \& \operatorname{lng}=$ pt\&nrm $=$ iso $>$, acesso em: 08 ago. 2017. Além disso, pode-se consultar a produção do Observatório do Ensino Médio da UFPR (www.observatoriodoensinomedio.ufpr.br) e da Associação Nacional de Pós-Graduação e Pesquisa e m Educação - ANPED. Disponível em:<http:// www.anped.org.br/news/reforma-do-ensino-medio-entenda-o-que-esta-em-jogo-e-vozesdesconsideradas-no-processo>, acesso em: 08/08/2017.

${ }^{4}$ De autoria da Comissão Especial destinada a promover estudos e proposições para a reformulação do Ensino Médio - CEENSI, da Câmara dos Deputados, criada em 2013 e presidida pelo Deputado Reginaldo Lopes, tendo como relator o Deputado Wilson Filho. Depois de pressões de movimentos sociais, a proposta inicial foi alterada em alguns pontos.

${ }^{5}$ O Decreto 2.208 de 17/12/1997 regulamenta o parágrafo $2^{\circ}$ do art. 36 e os art. 39 a 42 da LDB 9394/96, definindo os objetivos, a estrutura e a organização da educação 
profissional que passa a ter três níveis: básico, técnico e tecnológico. Nessa divisão, o ensino técnico corresponde ao ensino médio, podendo ser organizado concomitantemente ou posteriormente ao curso regular.

${ }^{6}$ ODecreto 5.154/04 de 23/07/2004 revogou o Decreto 2.208/97, trazendo como mudança central a oferta de forma articulada entre formação geral e profissional no currículo do ensino técnico.

${ }^{7}$ A EC 59 de 11/11/2009 altera o artigo 212 da Constituição Federal ampliando a obrigatoriedade do ensino para a faixa etária de quatro a dezessete anos, entre outras mudanças.

${ }^{8}$ Entre várias alterações na LDB 9394/96, a Lei 12.796 de 04/04/2013 incluiu o ensino médio como etapa obrigatória, adequando assim a lei à EC 59.

${ }^{9}$ A Resolução 753 da Secretaria Estadual de Educação de Minas Gerais, de 06 de janeiro de 2006, instituiu uma organização curricular que criou ênfases a partir do segundo (Ciências Humanas e Ciências da Natureza) e do terceiro (Ciências Humanas, Ciências Exatas e Ciências Biológicas) anos do ensino médio para 213 escolas do Projeto Escolas-Referência de 2004.

${ }^{10}$ Cf. "Reinventando o Ensino Médio - Caderno de Orientações." Belo Horizonte: Secretaria de Estado da Educação de Minas Gerais, 2014. Disponível em: https://www.educacao. mg.gov.br/images/stories/reinventando/REINVENTANDO_ENSINO_MEDIO_ CADERNO_ORIENTACOES_WEB.pdf. Acesso em: 02 fev. 2017.

${ }^{11}$ Instituído pela Portaria no 971, de 9 de outubro de 2009, no bojo das ações do Plano de Desenvolvimento da Educação - PDE.

${ }^{12}$ Em outubro de 2010, no Uruguai, o UNICEF promoveu o Seminário "Que ensino médio queremos?", com jovens representantes de diversos países reunidos pelo projeto Parlamento Juvenil do Mercosul. Disponível em: 01 mar. 2017 no link http://portal.mec. gov.br/index.php?option $=$ com_docman $\& v i e w=$ download $\&$ alias $=5661$-folder-parlamentojuvenil-mercosul\&category_slug=junho-2010-pdf\&Itemid=30192. Outro projeto iniciado em 2009, intitulado "Diálogos com o Ensino Médio", uma parceria do Observatório da Juventude da UFMG, o Observatório Jovem da UFF e a Secretaria de Educação Básica do MEC tinha como objetivo ampliar o conhecimento acerca da relação dos jovens com esse nível de ensino e fomentar o diálogo entre os diferentes atores sobre a sua realidade. Disponível em 01 mar. 2017 no link http://www.emdialogo.uff.br/.

${ }^{13}$ Trata-se de um movimento coordenado pelo advogado Miguel Nagib, que propõe a disseminação de projetos de lei nos três níveis do legislativo, a mobilização de políticos e partidos conservadores e de estudantes e pais para limitar a inserção no currículo e a manifestação dos professores em sala de aula de temas considerados como "doutrinação ideológica" ou que entram em conflito com as "convicções morais dos estudantes ou pais". Confira: http://www.programaescolasempartido.org/

${ }^{14}$ Por exemplo, Corti e Souza (2009), Silva e Oliveira (2016) e Fanfani (2012).

Submetido: $27 / 03 / 2017$

Aprovado: 06/09/2017

Contato:

Rua dos Aimorés, 1239 Apto. 1602 - Funcionários

Belo Horizonte $|\mathrm{MG}|$ Brasil

CEP 30.140-071 